\title{
Weaned age variation in the Virunga mountain gorillas (Gorilla beringei beringei): Influential factors
}

Winnie Eckardt ${ }^{1,2^{*}}$, Katie Fawcett ${ }^{2}$ \& Alison W. Fletcher ${ }^{1}$

${ }^{1}$ University of Chester, Department of Biological Science, Chester CH1 4BJ, UK, ${ }^{2}$ The

Dian Fossey Gorilla Fund International, Georgia 30315, USA, *Corresponding author. E-mail: winnie.eckardt@,gmail.com

Phone: $+250-(0) 788350016$

\begin{abstract}
Weaning marks an important milestone during life history in mammals indicating nutritional independence from the mother. Age at weaning is a key measure of maternal investment and care, affecting female reproductive rates, offspring survival and ultimately the viability of a population. Factors explaining weaned age variation in the endangered mountain gorilla are not yet well understood. This study investigated the impact of group size, group type (one-male versus multi-male), offspring sex, as well as maternal age, rank, and parity on weaned age variation in the Virunga mountain gorilla population. The status of nutritional independence was established in 69 offspring using long-term suckling observations. A Cox-regression with mixed effects was applied to model weaned age and its relationship with covariates. Findings indicate that offspring in one-male groups are more likely to be weaned earlier than offspring in multi-male groups, which may reflect a female reproductive strategy to reduce higher risk of infanticide in one-male groups. Inferior milk production capacity and conflicting resource allocation between their own and offspring growth may explain later weaning in primiparous mothers compared to multiparous mothers. Sex-biased weaned age related to maternal condition defined by parity, rank, and maternal age will be discussed
\end{abstract}


in the light of the Trivers-Willard hypothesis. Long-term demographic records revealed no disadvantage of early weaning for mother or offspring. Population growth and two peaks in weaned age within the Virunga population encourage future studies on the potential impact of bamboo shoots as a weaning food and other environmental factors on weaning.

Keywords: weaning, mountain gorilla, group, parity, dominance rank, offspring sex.

\section{Significance Statement}

Female reproductive rates are key in determining the viability of endangered populations. Using suckling observations from the Virunga mountain gorilla population spanning nearly forty years, we investigated factors affecting variation in age at weaning, a principal determinant of reproductive rate. Our findings provide evidence that females in one-male groups that have higher risk of infanticide wean offspring earlier than those in multi-male groups, that there is differential investment in males depending on age and reproductive experience of the mother, and that we should focus more on the availability of easily digestible foods (here bamboo) in relation to age at weaning. Improved understanding of such influencing factors enables us to more readily predict future population dynamics of these great apes as they grow towards their carrying capacity with continued change in their environment.

\section{Introduction}

Lactation is a distinct feature of mammals and has been subject to highly diverse and complex selection pressures (Hayssen 1993; van Noordwijk et al. 2013). Offspring age at the termination of direct nutritional support by the mother, here referred to as 'weaned age', is a measure of a mother's investment and care (Clutton-Brock 1991; Lee 
1996; Quinn 2013) as it can determine both female future reproductive rates and offspring fitness in mammals (Trivers 1972; Hayssen 1993; Lee 1996; Kennedy 2005). Suckling stimuli induce postpartum anovulation (see McNeilly 1979; Lee et al. 1991; McNeilly et al. 1994). Cessation of lactation has been linked to the resumption of cycling and re-conception in primates (Pharye's leaf monkeys [Trachypithecus phayrei crepusculus]: Borries et al. 2014) and may be triggered by a steady energy gain (Toba women: Ellison and Valeggia, 2003; Valeggia and Ellison, 2004; chimpanzees [Pan troglodytes]: Thompson et al. 2012). A mother needs to balance costs and benefits of the timing of weaning to maximise her lifetime reproductive success, measured by the survival and fecundity of current dependent offspring, and the mother's capacity to produce future offspring (Williams 1966; Trivers 1972, 1974; Fairbanks and McGuire 1995; Lee 1996). Premature weaning can reduce the offspring's chance of survival and future reproductive success, due to potentially higher morbidity risks and restricted growth and development respectively, while delayed weaning can reduce mother's future reproductive success through a prolonged anovulation period and increasing energetic costs, leading to the depletion of nutritional reserves (Trivers 1972; Lee 1996; Kennedy 2005).

\section{Factors influencing variation in weaned age}

Weaned age varies greatly within and among mammalian species, including humans, and has been attributed to various, often interrelated, factors encompassing ecological and social conditions, mother's ability to cope with the offspring's nutritional demands, and offspring characteristics. Ecological determinants of weaned age include food availability, predation risk, climate, and the degree of environmental uncertainty (nonhuman primates: Lee 1984, 1996; Boinski 1987; Lee et al. 1991; Lycett et al. 1998; Nowell 2005; other mammals: Low 1978; Arnold et al. 1979; Kleiman 1981; Carlisle 
1982; Blumstein and Foggin 1997; Fisher et al. 2002). For example, dichotomous adaptation in anti-predator strategies can explain weaned age differences in ungulates, with fawn of 'hiders' being weaned earlier than fawn of 'followers', as the latter may have to allocate more of the energy gained from milk to locomotion activities, resulting in slower growth rates (Fisher et al. 2002). When food is scarce and unpredictable, early weaning can increase the offspring's mortality risk but also improve the mother's chance of survival (Low 1978; Carlisle 1982). In many field and experimental studies, extremely poor, stressful, and uncertain environmental conditions have been associated with early weaning, suggesting that parents increase their own chance of survival by reducing survival of offspring which are of lower reproductive value (Tait 1980; Carlisle 1982; Lee 1984; Laurien-Kehnen and Trillmich 2004). In addition, a comparative study of placental mammals and marsupials suggests that high environmental uncertainty, e.g. irregular drought, that is associated with a high infant mortality but which is out of the control of parental effort, has exerted a strong selection pressure on parental investment strategies of Australian marsupials, favouring early weaning (Low 1978). In contrast, a comparative study on wild baboon populations (Papio cynocephalus ursinus) ranging between high- and low-quality habitat found delayed weaned age was linked to poor habitat quality (Lycett et al. 1998). The authors explained this through different levels of predation risk between habitats, largely independent of maternal effort, and driving weaning strategies in P. cynocephalus ursinus. In Galapagos fur seals (Arctocephalus galapagoensis), temporal adjustments in weaning strategies towards early termination have been observed during years with high food availability (Trillmich 1986). All of these studies demonstrate the importance of taking into account the mother's ability, or lack of it, to influence offspring mortality, when investigating evolution and variation in maternal investment strategies as well as 
the fact that future reproductive value may be altered by certain ecological factors (see Pennington and Harpending 1988).

Quality of social environment can affect the age at weaning (Lee 1996; brown bear [Urus artus]: Dahle and Swenson 2003; Phayre's leaf monkeys, [Trachypithecus phayrei]: Borries et al. 2014; human: Kaufman and Hall 1989). For instance, offspring in large groups of Phayre's leaf monkey reach nutritional independence later than those in small groups, which may reflect slower infant development when foraging costs rise with growing group size (Borries et al. 2014). In house mice, offspring of small litters are weaned earlier than those of large litters as they grow faster and reach the threshold body weight for weaning earlier (Koenig and Mark1 1987; Lee 1996). Extremely late weaned age occurs in semi-solitary living orangutans (Pongo pygmaeus abelii) ( solitary lifestyle hypothesis: van Noordwijk and van Schaik 2005) compared to other more gregarious great apes (Stewart 1981; Watts and Pusey 1993; Pusey et al. 1997; Nowell and Fletcher 2007). Orangutan females wean their offspring when those offspring have acquired sufficient ecological knowledge skills to survive in habitats where food is unpredictable and often scarce.

Variations in weaned age have also been linked to maternal condition, i.e. a measure of the mother's ability to cope with offspring's nutritional demands, involving parity, maternal age and dominance rank. In several species, milk secretion capability (quantity and quality) increases with parity (humans: Amatayakul et al. 1999; macaques: Tanaka 1997; Hinde 2009; Hinde et al. 2009; seals: Lang et al. 2012; cows: Miller et al. 2006; sheep: Sevi et al. 2000; rabbits: Xiccato et al. 2004) which can translate into delayed weaning for primiparous mothers (rabbits: Xiccato et al. 2004; humans: Akter and Rahman 2010). Maternal age is a determinant of reproductive rates in female mammals (Lee 1996) and in young women has been associated with early 
weaning (Baxter et al. 2009; Wijndaele et al. 2009). In primates, female dominance rank is probably the most commonly used proxy of maternal condition (Brown 2001; Grant 2003). Rank can reflect the nutritional status of females and relates to their level of testosterone, and both these can affect reproductive processes such as increased fertility and birth sex ratio, respectively (see review by Harcourt 1987; Grant 2003). However, studies that have used rank as a proxy for maternal condition have produced conflicting results. For example, high-ranking female vervet monkeys (Cercopithecus aethiops) with priority of food access wean their offspring at an earlier age than lowranking females (Whitten 1983), whereas rank-related effects on weaned age were absent in olive baboons (Papio anubis) (Smuts and Nicolson 1989).

When sex differences in reproductive success occur, maternal investment is expected in favour of the sex which provides more grand-offspring (Hamilton 1967; Trivers and Willard 1973). Across mammal species though, there is limited evidence for sex-bias in weaned age. The most consistent findings have emerged from studies of pinnipeds that have polygynous mating systems and show a high sexual dimorphism in body size. Male seal pups, who will attain a much larger adult size than females, are weaned later than female pups (Northern elephant seal [Mirounga angustirostris]: Reiter et al. 1978; Galapagos fur seal [Arctocephalus galapagoensis]: Trillmich 1986; Antarctic fur seal [Arctocephalus gazella]: Lunn and Arnould 1997). A sex-bias in weaned age in favor of sons also emerged in wild spider monkeys (Symington 1987), although in primates generally there is a lack of sex differences in weaned age (Brown 2001). In contrast, daughters which inherit the dominance status of their mothers are weaned later than sons in pronghorn antelopes (Antilocapra americana) (Hewison and Gaillard 1999). 
Several models have been used to predict the crucial mechanism(s) affecting adjustment of sex-biased maternal investment. The Trivers-Willard hypothesis (Trivers and Willard 1973) postulates that natural selection should favour mothers who are able to adjust their investment with respect to maternal condition, with those in good condition investing more in the sex of offspring with the greatest potential fitness return. Underlying model assumptions are that mothers in good condition produce offspring in good condition by the end of maternal investment, an advantage that is maintained into adulthood and that male and female offspring benefit differently, in terms of their future reproductive success, from additional resources received from mothers in good condition. The 'local resource competition' model predicts sex-biased maternal investment toward the dispersing sex, thus decreasing local competition between parent and their philopatric offspring (Clark 1978; Johnson 1988). Later, this model was modified by adding dominance rank 'inheritance' as key factor (Simpson and Simpson 1982), known as 'advantage-daughter' model (Altmann 1980) and 'local resource enhancement' model (Gowaty and Lennartz 1985), stating that in female philopatric societies raising daughters is more costly than raising sons because additional females in the group cause an increase in competition for limited resources.

In Virunga mountain gorillas, dispersal from the natal group is common for both sexes (Watts 1980; Robbins 1995) and mating occurs all year round (Stewart 1988; Gerald 1995). They also lack natural predators (Schaller 1963) and predominantly feed on abundant foliage, which is relatively evenly distributed in time and space (Fossey and Harcourt 1977; Vedder 1984; Watts 1984; McNeilage 1995), with the only exception being bamboo shoots (Yushania alpine), a bi-annual food resource (Fossey and Harcourt 1977; Vedder 1984; Watts 1998). Thus, the 'local resource competition' model and 'local resource enhancement model' are unlikely to determine maternal 
investment. However, the Trivers-Willard hypothesis could apply to the mountain gorilla, given their high sexual dimorphism in body size (Taylor 1997) and polygynous mating system (Harcourt and Stewart 2007), resulting in a greater variance in reproductive success in males than female gorillas (Bradley et al. 2005).

Long-term demographic records of Virunga mountain gorillas from 1967-2012 revealed effects related to proxies of maternal condition. Inter-birth intervals (IBIs), commonly used as proxy of maternal investment, were $20 \%$ longer for primiparous females than for multiparous females and infant mortality was $50 \%$ higher for primiparous mothers (Robbins et al. 2006) which would be expected if young females start to reproduce before completing their own growth and thus face a tradeoff between investing in their growth and investing in reproduction (Bercovitch et al. 2000; Künkele and Kenagy 2013). Age-specific female reproductive success followed a quadratic relationship, with relatively low success for the youngest and oldest females (Robbins et al. 2006). Mountain gorilla females also develop detectable dominance relationships which are not inherited (Harcourt and Stewart 1987; Watts 1994; Robbins et al. 2005) and IBIs could be partly explained by female's rank, with shorter IBIs in high-ranking females than in low-ranking females (Robbins et al. 2007a). Additionally, high-ranking females had longer IBIs after giving birth to sons than to daughters, whereas lowranking females had shorter IBIs after daughters. Given that such effects could result partly from variation in maternal condition and IBIs should depend partly on age at weaning (Borries et al. 2014), we might expect similar condition-related effects on weaned age and a similar quadratic relationship between maternal age and weaned age.

The folivorous diet may be responsible for relatively early weaning in mountain gorillas compared to other nonhuman great apes (Lee and Kappeler 2003; Nowell and Fletcher 2007) which are more reliant on less predictable, unevenly distributed fruit 
resources (Tutin and Fernandez 1993; van Noordwijk and van Schaik 2005). In addition, there is a higher risk of infanticide risk in this species (see Parker 1999; Nowell 2005); mothers with dependent offspring are most vulnerable to infanticide attacks from extra-group males (Watts 1989) and such males may kill dependent offspring resulting in earlier re-conception (Hrydy 1974).

Most studies of wild mammalian populations have focused on variation in indirect measures of maternal care and investment, such as IBI patterns and offspring survival. However, relying only on indirect measures can mask true effects. For example, varying length of lactation into subsequent pregnancy (Eckardt 2010; Borries et al. 2014), miscarriages, and unsuccessful conception may all cause discrepancies between IBIs and the actual weaned age. Comparatively few studies provide information on weaned age as either a direct measure of the length of lactation or close approximation of age at independence (Borries et al. 2014). This omission stems from challenges in establishing weaning status, especially in wild settings, where regular observations of suckling behavior are necessary, often over several years, both day and night, and where distinguishing real milk intake from comfort suckling (see Cameron, 1998; Reitsema, 2012) is important.

In this study, we used data on diurnal suckling by wild mountain gorilla offspring, collected over five study periods, to investigate variation in weaned age in relation to variation in group size, group type (one-male versus multi-male group), offspring sex, and maternal parity, dominance rank, and age. We further tested the suitability of using IBIs as indicator of weaned age. We used demographic data to explore potential consequences of weaned age variation for offspring and mother, including offspring age at first parturition and death, survival of mother's subsequent 
offspring beyond year one, and the timing of re-conception relative to completed weaning.

\section{Methods}

\section{Study site and subjects}

The study focused on habituated wild Virunga mountain gorillas in the Parc National des Volcans, Rwanda. All study individuals, observed over five different field periods (Table 1), were members of research groups that have been monitored by the Karisoke Research Center since 1967, including Group 4, Group 5, and Groups: Nunki, Beetsme, Pablo, Shinda, Kuryama, Titus, Ugenda, Ntambara, Urugamba, Isabukuru, Inshuti, and Bwenge (Table 2). Only mothers and their current offspring at time of observation were included in the study.

\section{Data collection}

Different measures are commonly applied to assess weaning (see review by Borries et al. 2014). Age at last nipple contact is proposed to best reflect offspring independence and capability to survive (Borries et al. 2014). In this study, weaning status was derived from diurnal suckling observations. Recording and sampling rules differed between study periods. None of the study periods used blinded recording methods because our study involved focal animals in the field. In 1973 and 1977, behaviour sampling on all mothers and offspring in view was conducted at 1-min intervals (Stewart 1988). In 1981-1983, focal sampling sessions (Altmann 1974) lasting 30 minutes (Stewart 1988) to five hours (Fletcher 1994; Eckardt 2010) were conducted on mothers and offspring at least once per month, where possible. During focal sessions, suckling was recorded in 30-sec intervals (Stewart 1988) or continuously 
(Fletcher 1994; Eckardt 2010). Suckling behavior was also recorded ad libitum on nonfocal subjects throughout each group visit by research assistants in 1981-1983. Weaned age was defined as being between the last observed suckling event and the following month. For example, if an offspring was last suckling at the age of 36 months, weaned age was estimated at 36.5 months. Seven offspring were weaned during a period of two or more months without data collection due to logistical difficulties in the field, leading to less accurate weaned ages. In such cases, the termination of weaning was assumed to have taken place between the date of the last suckling observation and the date of the subsequent observation without suckling events. The accuracy of the weaned age thus ranged from one day (weaning through emigration of mother) up to five months (median $/$ mean accuracy $=1 / 1.5$ months).

\section{Data analysis}

A Cox proportional-hazards regression for survival data (Cox 1972) with mixed effects (Therneau 2015) was used to model offspring weaned age and to examine its relationship to other predictor variables. The dataset included right-censored observations, due to offspring who were not fully weaned at the end of the observation period or who died during the observation period (Table 1). When weaning was induced through maternal death, those data were not considered in the data analysis. Only offspring who were at least 21 months old at the end of the observation period were involved in the analysis, since weaning by the mother has never been observed earlier than this in mountain gorillas. The youngest known age at which an offspring was observed to be naturally weaned (excluding weaning by death of the mother or separation from the mother) was 22 months (Stewart 1981). The weaning stage of offspring $(0=$ not weaned, $1=$ weaned $)$ was defined as the status variable and weaned age, measured in months, was set as the time variable. The model returns hazard ratios 
$(H R)$. A $H R$ above " 1 " indicates that this group of interest is more likely to be weaned, whereas a $H R$ less than " 1 " indicates that the group of interest is less likely to be weaned. If $H R$ equals “ 1 ”, there was no difference between groups of interest. Cox models were carried out in R version 2.13.0 using 'coxme' package version 2.2.-5 (Therneau 2015).

\section{Predictor variables}

The offspring sex, mean monthly group size from birth to completed weaning, including all age-sex classes, group type (one-male and multi-male), mother's parity (primiparous and multiparous), mother's age and dominance rank (high-ranking and low-ranking) were entered in the survival analysis as predictor variables. Two offspring (field period 1973-1977) were born into a one-male group which turned into a multimale group, following the maturation of a young male before weaning. The offspring group type was categorized as multi-male since blackbacks help silverbacks to defend the group (Yamagiwa 1987). Reproductive performance is reduced for young and old female mountain gorillas (Robbins et al. 2006). Thus, the squared term of maternal age was also included as a predictor variable. Females in each group were divided into high (top 50\%) and low rank (bottom 50\%) without adjusting for the number of females in each group following previous maternal investment studies (Robbins et al. 2007a, b). The rank of mothers during the first three field periods was extracted from published dominance matrices (Robbins et al. 2005). For the two most recent field periods, mothers' ranks were calculated using established methods (Robbins et al. 2005). From all field periods, we excluded females below the age of eight years from dominance matrices since these were below the age considered to represent adult females (Harcourt et al. 1980). For nine mother-offspring pairs the female's rank could not be clearly categorized. To test whether weaned age pattern provides support for the Trivers- 
Willard hypothesis, we considered interactions between offspring sex and commonly used proxies of maternal condition defined by parity, rank and mean age. As a female's rank may play a more important role with growing group size (Robbins et al. 2007b), the interaction between mother's rank and group size was also entered as a covariate in the model.

\section{Random effects}

Seventeen out of 46 study mothers were represented twice in the longitudinal dataset with subsequent offspring and three mothers were presented three times. To account for repeated measures, we included mother's identity as a random effect nested in their social group. As weaned age data were collected during distinct field periods, field period was also treated as a random effect to control for clustered data design.

\section{Inter-birth interval as indicator of weaned age}

To examine whether inter-birth interval is a suitable indicator of weaned age, we correlated weaned age data with an accuracy of one month and better with the corresponding inter-birth interval $(\mathrm{N}=20)$ using the Spearman's rank correlation test.

\section{Consequences of weaned age variation}

Long-term demographic records collected from the study groups by the Karisoke Research Center were used to explore potential consequences of weaned age variation for offspring and mother including the age at first parturition in female offspring $(N=8)$, age at death of weaned offspring $(N=4)$, survival of subsequent offspring beyond the first year $(N=18)$ and the timing of re-conception relative to completed weaning $(N=16)$. For these analyses, we also considered only weaned age data with an accuracy of at least one month. Spearman's rank correlation tests were conducted to examine the relationship between weaned age and age at first parturition, age at death and the timing of re-conception relative to the completed weaning. The re- 
conception date was approximated by subtracting the median gestation length of 255 days in the population (Harcourt et al. 1980) from the date of the mother's subsequent parturition. We then calculated the relative time gap between re-conception and completed weaning. Negative values represented re-conception after weaning, while positive values indicated re-conception before weaning was completed. The MannWhitney U test for two-independent samples was used to compare weaned ages of two sets of offspring, those with subsequent siblings surviving the first year of life and those with subsequent sibling who died before reaching one year.

\section{Results}

When considering only offspring with a weaned age accuracy of one month or better $(N=27)$, the mean weaned age was 39.9 months (median $=40)$. Including all weaned offspring $(n=34)$ increased the mean to 40.8 months $($ median $=40.5)$. The distribution of weaned ages was bimodal, with peaks at relatively early age (35-40 months) and a relatively late age (45-50 months) (Fig. 1); thus the mean may not be biologically meaningful.

\section{Cox proportional-hazards regression model output}

\section{Group characteristics}

Group type had the strongest effect on weaned age, with offspring growing up in one-male groups $(N=17)$ being on average $\sim 13$ times more likely to be weaned earlier than offspring growing up in multi-male groups $(\mathrm{N}=52)($ Fig. $2 ; H R=13.18, z=3.38$, $p<0.001)$. Two females had offspring with known weaned age in one-male and multimale groups. Although no statistical test could be performed, the early weaned ages of their offspring born into one-male groups (37 and 29 months) compared to weaned ages 
of their offspring born into multi-male groups (45.5 and 45 months respectively) were in line with the statistical group type effect on weaned age.

One-male groups were significantly smaller $(N=17$, mean $\pm \mathrm{SD}=10.3 \pm 3.2)$ than multi-male groups $(N=52$, mean $\pm \mathrm{SD}=27.2 \pm 16.7)$ (Mann-Whitney $\mathrm{U}$ test: $N=$ $69, W=789, p<0.001)$. To disentangle the effect of group type from the effect of group size, we re-ran the model for one-male and multi-male groups separately. If the group type effect is simply reflecting a group size effect, weaned age should increase with group size. However, there was no effect of group size in one-male groups $(H R=$ $0.63, z=-1.18, p=0.240$ ), whereas offspring in multi-male groups were weaned earlier with increasing group size $(H R=1.05, z=1.99, p=0.047)$, suggesting that the group type effect was independent of group size.

The effect of group size on weaned age depended on the mother's rank. The larger the group, the earlier low-ranking females weaned offspring $(H R=1.10, z=3.44$, $p=0.012)$, but this wasn't the case for high-ranking females $(H R=1.01, z=0.33, p=$ $0.740)$.

\section{Characteristics of mother and offspring}

Overall, weaned age of daughters varied more than weaned age of sons (Fig. 3, coefficient of variation $[\mathrm{CV}]: C V$ daughters $\left.=25.1, C V_{\text {sons }}=13.7\right)$. The three earliest weaned ages $(22,28,29$ months) were recorded for daughters of mid-aged multiparous mothers with unclassified or high rank, while the latest weaned individual (57 months) was observed in the daughter of a young, primiparous mother with low rank.

Furthermore, the likelihood of being weaned early reduced with increasing age of the mother $(H R=0.56, z=2.03, p=0.042)$. Although the squared term of maternal age did not reach statistical significance, its positive $z$-value $(H R=1.01, z=1.58, p=$ 
0.120) indicates a slightly convex weaned age curve for maternal age, with higher weaned age in young and older mothers compared to mid-aged mothers (Fig. 4). The group type effect was not caused by different age patterns of females in one-male and multi-male groups (Mann-Whitney U test: $N_{\text {multi }}=52, N_{\text {one }}=17, W=400, p=0.563$ ).

Primiparious mothers weaned their offspring later $(N=13$, mean weaned age \pm $\mathrm{SD}=43.7 \pm 7.9$ months $)$ than multiparous mothers $(N=21$, mean weaned age $\pm \mathrm{SD}=$ $39 \pm 7.8$ months $)(H R=0.08, \mathrm{z}=-2.14, p=0.032)$. Considering that weaned age increased with maternal age and primiparous mothers were younger $(N=24$, mean age $\pm \mathrm{SD}=12.4 \pm 4)$ than multipares $(N=45$, mean age $\pm \mathrm{SD}=24 \pm 6.2$ years) (Fig. 4 , Mann-Whitney U test: $W=1034, p<0.001$ ), we would expect opposite parity patterns. This contradiction might be caused by late weaned ages in the oldest multipares (Fig. 4).

There was no difference in weaned age between sexes $(H R=6.25, z=1.74, p=$ $0.082)$ and between high- and low-ranking females $(H R=1.29, z=0.60, p=0.550)$. However, weaned age tended to depend on female rank $(H R=6.25, z=1.47, p=$ 0.082). High-ranking mothers weaned sons significantly later than daughters $(H R=$ $0.18, z=-2.36, p=0.018)$. A reversed sex-bias in weaned age was not found within low-ranking mothers $(H R=1.10, z=0.13, p=0.900)$.

Low-ranking females were younger $(N=25$, mean age $\pm \mathrm{SD}=16.2 \pm 7.3)$ compared to high-ranking females $(N=35$, mean age $\pm \mathrm{SD}=22.8 \pm 7.3)$ (MannWhitney $\mathrm{U}$ test: $W=654, p=0.001)$ and included a higher proportion of primiparous mothers $(64 \%)$ than high-ranking females $(14 \%)\left(N=60, X^{2}=15.84, p<0.001\right)$. As maternal condition might vary predictably with maternal age and parity, we re-ran two separate models entering offspring sex in interaction with either maternal age or parity. The effect of offspring sex depended on parity $(H R=10.34, z=2.31, p=0.021)$. 
Multiparous mothers weaned daughters earlier than sons $(H R=0.14, z=-2.73, p=$ $0.006)$ while no sex difference occurred in primiparous mothers $(H R=1.46, z=0.53, p$ $=0.600)$. The effect of maternal age also depended on offspring sex. Sons were weaned earlier by young and old mothers than by mid-aged mothers (maternal age $\mathrm{x}$ son: $H R=$ $0.48, z=-2.10, p=0.036$; maternal age ${ }^{2} \mathrm{x}$ sex: $\left.H R=1.01, z=1.98, p=0.048\right)$, whereas maternal age had no effect on weaned age of daughters (maternal age $\mathrm{x}$ daughters: $H R=$ $1.00, z=-0.01, p=0.990$; maternal age ${ }^{2} \mathrm{x}$ sex: $\left.H R=1.00, z=-0.37, p=0.710\right)$. These findings suggest that mid-aged, high-ranking, multiparous females invest more in sons than in daughters in form of later weaning, and that only primiparous females provide milk longer to their daughters than sons.

A summary of tested variables and their effect on weaned age is provided in Table 3. To ensure that offspring with low accuracy of weaned age in the data set did not produce unreliable results, we re-ran the Cox-model but without offspring whose weaned age accuracy was less than one month $(N=61)$. Apart from the interaction effect of offspring sex with parity $(p=0.062)$ and maternal age (maternal age \& sons: $p$

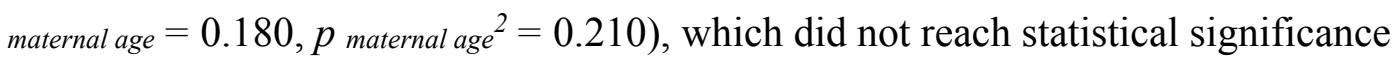
anymore, the importance of the remaining predictors in the model did not change.

\section{Inter-birth interval as indicator of weaned age}

Weaned age with an accuracy of one month or better showed a strong positive correlation with length of subsequent inter-birth intervals (IBIs) $\left(N=20, r_{S}=0.678, p=\right.$ 0.001, Fig. 5). The discrepancy between weaned age and IBIs ranged from 0 to 20.5 months (mean $\pm \mathrm{SD}=9.5 \pm 4.9$ months).

\section{Consequences of weaned age}


Historical demographic records to investigate consequences of weaned age variation on offspring survival and fitness are still few. Preliminary findings suggest that weaned age is unrelated to age at first parturition (mean $\pm \mathrm{SD}=11.2 \pm 1.5$ years, $N$ $\left.=8, r_{S}=-0.357, p=0.389\right)$. Timing of re-conception by a mother relative to completed weaning was also unrelated to weaned age (mean $\pm \mathrm{SD}=4 \pm 132$ days, $N=16, r_{S}=$ $0.165, p=0.541$, Fig. 6$)$.

Age at death and completed weaning were available for four out of 34 gorillas showing no relationship $\left(N=4, r_{s}=0.2, p=0.917\right)$. Twenty two weaned offspring were still alive at the end of 2012 (age range: 3.8 - 25.2 years, weaned age range: $28-$ 57 months) suggesting that there is no strong impact of weaned age on offspring survival. The life history of seven weaned offspring remains unknown due to emigration events. One offspring died due to anthropogenic influences.

Mothers' subsequent offspring who survived the first year were linked to an earlier weaned age of the previous offspring compared to mothers' subsequent offspring who died before the age of one (Mann-Whitney U test: $N_{\text {survived }}=13, N_{\text {died }}=5, W=$ $57, p=0.014$, Fig. 7). This difference was not caused by different age distribution in both groups of mothers (Mann-Whitney $\mathrm{U}$ test: $W=34, p=0.920$ ).

\section{Discussion}

The primary goal of this study was to investigate factors that may explain weaned age variation in the endangered Virunga mountain gorillas, combining data from five different study periods. Weaned age was strongly associated with group type, being higher in multi-male groups than single male groups but was not associated with group size. In mountain gorillas, multi-male groups face lower infanticide risks and have higher offspring survival than one-male groups (Watts 2000; Robbins et al. 2007b; 
Robbins et al. 2013), this may explain later weaning in these groups. Mothers with dependent offspring are vulnerable to infanticidal attacks by external silverbacks during inter-unit interactions or after the death of the group leader (Watts 1989; Robbins et al. 2007b). Therefore, females in one-male groups can benefit by weaning offspring early because of resumption of ovulation and infanticide risk. Exposure to high infanticide risk can cause stress (baboons [Papio hamadryas spp.]: Engh et al. 2006), reflected in increased cortisol levels (Romero 2004). In turn, high levels of cortisol in mother's milk can trigger faster infant weight gain by altering offspring behavioral phenotype and metabolism (rhesus macaques [Macaca mulatta]: Hinde et al. 2015). As age at weaning is linked to a threshold weight of roughly four times the neonatal birth weight in many mammals including primates (Clutton-Brock 1991; Lee et al. 1991; Lee 1996), maternal cortisol transferred to offspring through milk might contribute to regulation of an infant's development trajectory and thus weaned age (Love et al. 2013; Hinde et al. 2015).

In some cases, cortisol levels are positively associated with group size (e.g., male spotted hyenas [Crocuta crocuta]: Goymann et al. 2003) and/or negatively associated with rank (e.g., review: Creel et al. 2013; female spotted hyena [Crocuta crocuta]: Goymann et al. 2001). Cortisol might contribute to variation in weaned age in mountain gorillas, if levels are also inversely related to rank among females. However, cortisol and rank in nonhuman primates show complex relationships (olive baboons, Sapolsky 1982; Japanese macaques, Macaca fuscata, Barrett et al. 2002; review by Goymann and Wingfield 2004; baboons, Papio cynocephalus, Gesquiere et al. 2011; review by Creel et al. 2013; chimpanzees, Pan troglodytes schweinfurthii, Markham et al. 2013). To better understand the effect of group size on weaned age, especially when 
multi-male groups grow beyond the size of the largest one-male group composed of 15 gorillas in this dataset, more data are required.

Group type (one- or multi-male) had no effect on inter-birth intervals (IBIs) of mountain gorillas (Robbins et al. 2007b, 2013). Different relationships of IBI and weaned age with group type despite the strong relationship between IBI and weaned age suggest that direct behavioural measures of maternal investment and care need to be integrated into studies of female reproductive strategies. However, discrepancy between measures may be caused by small sample size and the use of nipple contact rather than actual milk intake to assess weaned age in this study (see Cameron 1998). Recent noninvasive techniques enable assessment of stable carbon and nitrogen isotope ratios from fecal samples, indicating plant versus animal (including milk) food intake, and could be used in future to assess weaning status more reliably (Reitsema 2012).

\section{Offspring sex and maternal condition}

Greater variation in weaned age in daughters compared to in sons may indicate limited capacity to influence early maternal investment in sons due to neonatal sexual dimorphism, reflected in higher birth body mass in gorilla males than in females (Meder 1990; Leigh and Shea 1996), and higher metabolic requirements in male infants (Clutton-Brock et al. 1985). Thus, raising sons may mean greater lactational demands on mountain gorilla mothers and less ability to adjust weaned age. Galápagos sea lion offspring (Zalophus wollebaeki) show neonatal sexual dimorphism and have varying lactational demands associated with the level of independent feeding, indicating an offspring's contribution to its own survival and growth (Piedrahita et al. 2014). Thus, the mother's supply of resources and offspring's food intake through independent feeding should to be studied concurrently to understand sex-biased investment and underlying behavioral mechanism in mammals (see Royle et al. 2004). 
Primiparous mothers weaned their offspring at later ages than their multiparous counterparts consistent with findings on IBIs (Robbins et al. 2007a), whereas weaned age was not affected by female rank which contrasts with findings on IBIs. This suggests that parity might be a better proxy of maternal reproductive condition in mountain gorillas than female rank. Primipares compared to multipares may have impaired reproductive success (see review by Anderson 1986; Bercovitch et al. 1998; Robbins et al. 2006), lack maternal experience and skills leading to lower efficiency of maternal investment and may face a conflict between allocating energy resources to the offspring while still investing in their own growth (Bercovitch et al. 2000; Künkele and Kenagy 2013). It should be also considered that accounting for the number of adult females in a group when allocating ranks to females may be important as consequences of being high- or low-ranking is likely to be affected by the presence of competitors.

Similar to findings on IBIs (Robbins et al. 2007a) and suckling frequency (Eckardt 2010), sex-differences in weaned age depend on proxies of maternal condition, defined by rank, parity, and age. High-ranking and multiparous females weaned sons later than daughters. However, reversed sex-bias patterns in weaned age consistent with Trivers-Willard hypothesis (1973) did not occur for rank, parity, and age. Later weaning in primiparous mothers and in sons of the oldest females, supports previous findings in mountain gorillas and other primate species suggesting an inverted U-shaped curve with relatively low reproductive performance in the young primipares and in the oldest females (Caro et al. 1995; Robbins et al. 2006). Despite a lack of extended postreproductive lifespan in female mountain gorillas, five out of seven miscarriages were observed in multiparous mothers above the age of 27 which may reflect a reduced physiological capacity to reproduce in older females (Robbins et al. 2006); uterine and ovarian aging has been associated with declining fertility in aging women (Frank et al. 
1994), rodents (Kong et al. 2012), red deer (Cervus elaphus) (Fisher et al. 2000) and Japanese macaques (Nozaki et al. 1995). Thus, our findings also lend some support for the terminal investment hypothesis which predicts that aging females invest more in their current offspring as their reproductive value declines (see review by Caro et al. 1995).

Support for the Trivers-Willard hypothesis (1973) from different measures of maternal investment in mountain gorillas (i.e. IBIs and weaned age) is limited, and it remains questionable if this hypothesis can ever be proven or disproved in mammals, especially in those with slow reproduction rates and relatively long life span. Our study tested a population of females over limited periods (Carranza 2002) rather than individual mothers over different reproductive efforts as proposed by Cameron and Linklater (2002). Long-term effects of variation in weaned age will be more conclusive as combined data on weaned age and reproductive success of offspring accumulate. Furthermore, we currently lack evidence for two assumptions of the Trivers-Willard hypothesis; namely, that females in good condition produce offspring in good condition by the end of the maternal investment period, and that the advantage gained through being in good condition maintains into adulthood. Assessing energy balance of mother and offspring using urinary C-peptide measures (see Grueter et al. 2014) would allow monitoring how mother's energetic budget translates into offspring energetic budget and growth trajectory throughout the period of maternal investment and beyond. Growth rates in wild animals can be assessed reliably through photogrammetry (Breuer et al. 2007; Caillaud et al. 2008; Abavandimwe et al. 2015). Preliminary results provide no support that early weaning is disadvantageous for mother and offspring. Subsequent offspring of mothers who weaned offspring early also had a higher survival chance 
indicating that mothers who wean early can also still succeed: "Do what you can, with what you have, where you are" (Roosevelt 1913, ch. 9).

\section{Two weaning peaks - evidence of seasonality in weaning?}

Mountain gorillas in the Virungas face only limited temporal variation in food abundance (Fossey and Harcourt 1977; Vedder 1984; Watts 1984); thus it is unsurprising that they are not seasonal breeders (Stewart 1988). However, in 2007, five offspring were weaned during a rich bamboo-shoot season. Bamboo shoot (Yushania alpine) is a highly preferred and only biannually available food item of mountain gorillas (Fossey and Harcourt 1977; Vedder 1984). A recent unpublished study on mechanical characteristics of food plants that make up $90 \%$ of the Virunga mountain gorilla diet revealed that bamboo shoots after removal of epithelium (as gorillas do before ingestion) has the lowest average toughness ( 250 joules/metre squared) (Glowacka H pers. communication, $25^{\text {th }}$ June and $18^{\text {th }}$ August 2013). Low toughness of food facilitates mastication for gorilla weanlings which are commonly equipped with only deciduous dentition and lack most of their molars (Godfrey et al. 2003) that are needed for processing mature foliage and seeds efficiently (Kay 1978). Bamboo shoots are thus a suitable food for gorilla weanlings in the Virunga mountains where large, soft fruit sources are absent (Harcourt and Stewart 2007), in contrast with Western lowland gorilla (Gorilla gorilla gorilla) habitat where fruits are the preferred weaning food in young gorillas (Nowell and Fletcher 2008). In addition, bamboo shoots are high in energy and protein compared to other gorilla food items (Grueter et al. 2014), which makes them a suitable replacement for milk. Higher concentrations of urinary C-peptide in female Virunga mountain gorillas during the bamboo shoot season compared to other seasons support higher energetic intakes when bamboo shoots are available (Grueter et al. 2014). The two peaks in weaned age were about six months apart; this corresponds 
with the typical six month interval between periods of bamboo shoot production (Fossey and Harcourt 1977; Vedder 1984), suggesting that seasonal access to supplementary weaning food may be more important for reproductive strategies in mountain gorillas than previously thought, and thus should be targeted in future investigations. As primates with seasonal mating patterns delay weaning to the subsequent mating season after missing a season (Lee and Kappeler 2003) gorilla mothers can wait to wean until the next bamboo shoot season with optimal weaning conditions. The alternative scenario allows mothers to wean earlier (see Lee 1996) despite impaired food processing competence of the weanling, due to supplementary weaning food provided by a rich bamboo shoot season. More weaned age data are required to confirm the bimodal distribution along data on bamboo phenology.

\section{Findings in the light of current population changes}

Through long-term and intensive conservation efforts in the Virungas, the mountain gorilla population is growing (Gray et al. 2013). This growth is resulting in higher group density and more solitary silverbacks in the population (Gray et al. 2013; Caillaud et al. 2014) leading to a sixfold increase in annual inter-unit interaction rates in the study groups (see Fig. 13 in Caillaud et al. 2014) and thus a potential increase in infanticide risk (Yamagiwa et al. 2009). Our findings suggest that continued population growth will exert an increasing selection pressure on maternal investment strategies in this population. Females, in particular those living in one-male groups with higher infanticide risk (Watts 2000), might "push" weaned age to the earliest possible developmental stage that allows successful weaning. To our knowledge the earliest age a mountain gorilla infant survived without milk provision by the mother was 22 months. However, a rare incident observed in November 2007 provided a unique perspective on 
the ability of offspring to survive without any nutritional or physical support of the mother proposing that total independence may not be possible at such a young age (Eckardt et al. 2007). Two infants died after a sudden separation from their mothers due one group split during an interaction with a solitary silverback at the age of 23 and 29 months whereas another 30 months old infant survived 18-days without his mother before being reunited showing signs of malnutrition similar to kwashiorkor in humans (Tierney et al. 2010). This reinforces the fact that nutritional independence is likely to be only one facet of true independence from the mother but also that weaning before 29 months is only possible if the mother remains in the group.

If maternal cortisol affects infant development trajectory (Love et al. 2013; Hinde et al. 2015), a higher frequency of stressful inter-unit interaction (Eckardt et al. 2014) might contribute to earlier weaned age adjustments in the population. This study suggests that the gestation-lactation overlap varies substantially among female mountain gorillas. It might be expected that females would increase the overlap between the current lactation period and the subsequent gestation through pressures from extra group males, with multiparous, mid-age mothers likely to be in a better position to engage in such energetically demanding strategies.

Further focus on maternal strategies in a changing social environment is warranted. For this to be possible, adult females with offspring approaching weaning age ( $\sim 2$ years) should be regularly tested for pregnancy (optimally once to twice a month) to provide precise data on the length of gestation-lactation overlap, but also to detect miscarriages more reliably.

The availability and abundance of the five key gorilla food plants has also been changing alongside the growth of the Virunga mountain population, with two (Galium spp., Laportea alatipes) of the five decreasing in abundance (Grueter et al. 2013). 
Continuing population growth may lead to increased food competition within groups which could be reflected in a stronger effect of mother's parity, rank, and maternal age on weaned age patterns. Such changing environmental factors demonstrate the importance of long-term research and monitoring of this key life history marker, weaned age, as well as of other associated measures of maternal investment, due to the importance of understanding their relationship with population dynamics of the Virunga mountain gorillas as they grow towards their carrying capacity.

\section{Acknowledgments}

We thank the Rwandan government and the Rwandan Development Board for their long-term support of the research and protection activities of the Dian Fossey Gorilla Fund's Karisoke Research Center. This work was funded by a University of Chester Gladstone fellowship. Data derived from AF was funded and supported by University of Bristol and Stephen Harris. We are very grateful to Kelly Stewart for her valuable contribution to the weaned age data set. We are indebted to all Karisoke research and field assistants who contributed to the data collection. We also thank Damien Caillaud and Donal Bisanzio for their advice during the process of statistical analysis. We would like to extend special thanks to both the anonymous reviewers and David Watts for their valuable contributions which improved this article significantly.

\section{Ethical Standards}

This study was funded by University of Chester Gladstone fellowship. We declare that the study complies with the current laws of the country in which it was conducted. All applicable international, national, and/or institutional guidelines for the care of animals 
were followed. This article does not contain any studies with human participants performed by any of the authors.

\section{References}

Abavandimwe D, Galbany J, Breuer T, Ndagijimana F, Stoinski T, McFarlin SC (2015) Body growth in wild mountain gorillas (Gorilla beringei beringei) from Volcanoes National Park, Rwanda. Am J Phys Anthropol 156:65 (abstract)

Akter S, Rahman MM (2010) Duration of breastfeeding and its determinants in Bangladesh. J Health Popul Nutr 28:595-601

Altmann J (1974) Observational study of behavior: Sampling methods. Behaviour 49:227-265

Altmann J (1980) Baboon mothers and infants. Harvard University Press, Cambridge, Massachusetts

Amatayakul K, Wongsawasdi L, Mangklabruks A, Mangklabruks A, Tansuhaj A, Ruckphaopunt S, Chiowanich P, Woolridge MM, Drewett RF, Baum JD (1999) Effects of parity on breastfeeding: a study in the rural setting in Northern Thailand. J Hum Lact 15:121-124

Anderson CM (1986) Female age: Male preference and reproductive success in primates. Int J Primatol 7:305-326

Arnold GW, Wallace SR, Maller RA (1979) Some factors envolved in natural weaning processes in sheep. Appl Anim Ethol 5:43-50

Barrett GM, Shimizu K, Bardi M, Asaba S, Mori A (2002) Endocrine correlates of rank, reproduction, and female-directed aggression in male Japanese macaques (Macaca fuscata). Horm Behav 42:85-96

Baxter J, Cooklin AR, Smith J (2009) Which mothers wean their babies prematurely from full breastfeeding? An Australian cohort study. Acta Paediatr 98:1274-1277

Bercovitch FB, Lebron MR, Martinez HS, Kessler MJ (1998) Primigravidity, body weight, and costs of rearing first offspring in rhesus macaques. Am J Primatol 46:135-144

Bercovitch FB, Widdig A, Nürnberg P (2000) Maternal investment in rhesus macaques (Macaca mulatta): maternal costs and consequences of raising sons. Behav Ecol Sociobiol 48:1-11

Blumstein DT, Foggin JM (1997) Effects of vegetative variation on weaning success, overwinter survival, and social group density in golden marmots (Marmota 
caudata aurea). J Zool 243:57-69

Boinski S (1987) Birth synchrony in squirrel monkeys (Saimiri oerstedi). Behav Ecol Sociobiol 21:393-400

Borries C, Lu A, Ossi-Lupo K, Larney E, Koenig A (2014) The meaning of weaning in wild Phayre's leaf monkeys: Last nipple contact, survival, and independence. Am J Phys Anthropol 154:291-301

Bradley BJ, Robbins MM, Williamson EA, Steklis HD, Gerald Steklis N, Eckhardt N, Boesch C, Vigilant L (2005) Mountain gorilla tug-of-war: silverbacks have limited control over reproduction in multimale groups. P Natl Acad Sci USA 102:94189423

Breuer T, Robbins MM, Boesch C (2007) Sexual dimorphism in wild Western gorillas (Gorilla gorilla). Am J Phys Anthropol 134:369-382

Brown GR (2001) Sex-biased investment in nonhuman primates: can Trivers and Willards theory be tested? Anim Behav 61:683-694

Caillaud D, Levréro F, Gatti S, Ménard N, Raymond M (2008) Influence of male morphology on male mating status and behavior during interunit encounters in western lowland gorillas. Am J Phys Anthropol 135:379-388

Caillaud D, Ndagijimana F, Giarrusso AJ et al (2014) Mountain gorilla ranging patterns: Influence of group size and group dynamics. Am J Primatol 76:730-746

Cameron E (1998) Is suckling behaviour a useful predictor of milk intake? A review. Anim Behav 56:521-532

Cameron EZ, Linklater WL (2002) Sex bias in studies of sex bias: the value of daughters to mothers in poor condition. Anim Behav 63:F5-F8

Carlisle TR (1982) Implications for parental care allocation. Anim Behav 30:824-836

Caro TM, Sellen DW, Parish A, Frank R, Brown DM, Voland E, Borgerhoff Mulder M (1995) Termination of reproduction in nonhuman and human female primates. Int $\mathrm{J}$ Primatol 16:205-220

Carranza J (2002) What did Trivers and Willard really predict? Anim Behav 63:f1-f3

Clark AB (1978) Sex ratio and local resource competition in a prosimian primate.

Science 201:163-165

Clutton-Brock TH (1991) The evolution of parental care. Princeton University Press, Oxford

Clutton-Brock TH, Albon SD, Guinness FE (1985) Parental investment and sex differences in juvenile mortality in birds and mammals. Nature 313:131-133

Cox DR (1972) Regression models and life-tables. J Roy Stat Soc B 34:187-220 
Creel S, Dantzer B, Goymann W, Rubenstein DR (2013) The ecology of stress : effects of the social environment. Functional Ecology 27:66-80

Dahle B, Swenson JE (2003) Factors influencing length of maternal care in brown bears (Ursus arctos) and its effect on offspring. Behav Ecol Sociobiol 54:352-358

Eckardt W (2010) Maternal investment in mountain gorillas (Gorilla beringei beringei). PhD-thesis, University of Chester

Eckardt W, Fawcett K, Fletcher AW (2007) Going it alone - Premature separation of mothers and infants in mountain gorillas. Primate Eye 92:14 (abstract), http://www.psgb.org/publications.php

Eckardt W, Stoinski TS, Santymire R (2014) Using non-invasive endocrinology to understand how the changing environment affects stress physiology in mountain gorillas (Gorilla beringei beringei). In: 25th International Primatological Society Congress. Hanoi, Vietnam (abstract)

Ellison PT, Valeggia CR (2003) C-peptide levels and the duration of lactational amenorrhea. Fertil Steril 80:1279

Engh A, Beehner J, Bergman T, Whitten P, Hoffmeier RR, Seyfarth RM, Cheney DL (2006) Female hierarchy instability, male immigration and infanticide increase glucocorticoid levels in female chacma baboons. Anim Behav 71:1227-1237

Fairbanks LA, McGuire MT (1995) Maternal condition and the quality of maternal care in vervet monkeys. Behaviour 132:733-754.

Fisher DO, Blomberg SP, Owens IPF (2002) Convergent maternal care strategies in ungulates and macropods. Evolution 56:167-176

Fisher MW, McLeod BJ, Heath DA, Lun S, Hurst PR (2000) Role of ovarian failure in reproductive senescence in aged red deer (Cervus elaphus) hinds. J Reprod Fertil $120: 211-216$

Fletcher AW (1994) The social development of immature mountain gorillas (Gorilla gorilla beringei). PhD-thesis, University of Bristol

Fossey D, Harcourt AH (1977) Feeding ecology of free-ranging mountain gorilla (Gorilla gorilla beringei). In: Clutton-Brock TH (ed) Primate ecology: studies of feeding and ranging behaviour in lemurs, monkeys, and apes. Academic Press, New York, pp 415-447

Frank O, Bianchi PG, Campana A (1994) The end of fertility: Age, fecundity and fecundability. J Biosoc Sci 26:349-368

Gerald CN (1995) Demography of the Virunga mountain gorilla (Gorilla gorilla beringei). PhD-thesis, Princeton University

Gesquiere LR, Learn NH, Simao MCM, Onyango PO, Alberts SC, Altmann J (2011) 
Life at the top: rank and stress in wild male baboons. Science 333:357-360

Godfrey LR, Samonds KE, Jungers WL, Sutherland MR (2003) Dental development and primate life histories. In: Kappeler PM, Pereira ME (eds) Primate life histories and socioecology. University of Chicago Press, Chicago, IL, pp 177-203

Gowaty PA, Lennartz MR (1985) Sex ratios of nestling and fledgling red-cockaded woodpeckers (Picoides borealis) favor males. Am Nat 126:347-353

Goymann W, East ML, Wachter B, Hőner OP, Mőstl E, van't Hof TJ, Hofer H (2001) Social, state-dependent and environmental of faecal corticosteroid modulation levels in female spotted hyenast free-ranging. Proc R Soc Lond B 268:2453-2459

Goymann W, East ML, Wachter B, Höner OP, Möstl E, Hofer H (2003) Social status does not predict corticosteroid levels in postdispersal male spotted hyenas. 43:474479

Goymann W, Wingfield JC (2004) Allostatic load, social status and stress hormones: The costs of social status matter. Anim Behav 67:591-602

Grant VJ (2003) The maternal dominance hypothesis: questioning Trivers and Willard. Evol Psychol 96-107.

Gray M, Roy J, Vigilant L, Fawcett K, Basabose A, Cranfield M, Uwingeli P, Mburanumwe I, Kagoda E, Robbins MM (2013) Genetic census reveals increased but uneven growth of a critically endangered mountain gorilla population. Biol Conserv 158:230-238

Grueter CC, Deschner T, Behringer V, Fawcett K, Robbins MM (2014) Socioecological correlates of energy balance using urinary $\mathrm{C}$-peptide measurements in wild female mountain gorillas. Physiol Behav 127:13-19

Grueter CC, Ndamiyabo F, Plumptre AJ, Abavandimwe D, Mundry R, Fawcett KA, Robbins MM (2013) Long-term temporal and spatial dynamics of food availability for endangered mountain gorillas in Volcanoes National Park, Rwanda. Am J Primatol 75:267-280

Hamilton WD (1967) Extraordinary sex ratios. Science 156:477-488

Harcourt AH, Fossey D, Stewart KJ, Watts DH (1980) Reproduction in wild gorillas and some comparison with chimpanzees. J Reprod Fertil Suppl 28:59-70

Harcourt AH, Stewart KJ (1987) The influence of help in contests on dominance rank in primates: hints from gorillas. Anim Behav 35:182-190

Harcourt AH, Stewart KJ (2007) Gorilla society: conflict, compromise, and cooperation between sexes. The University of Chicago Press, Chicago, IL

Hayssen V (1993) Empirical and theoretical constraints on the evolution of lactation. J Dairy Sci 76:3213-3233 
Hewison AJM, Gaillard J (1999) Successful sons or advantaged investment in ungulates. Trends Ecol Evol 14:229-234

Hinde K (2009) Richer milk for sons but more milk for daughters: Sex-biased investment during lactation varies with maternal life history in rhesus macaques. Am J Hum Biol 21:512-519

Hinde K, Power ML, Oftedal OT (2009) Rhesus macaque milk: Magnitude, sources, and consequences of individual variation over lactation. Am J Phys Anthropol 138:148-157

Hinde K, Skibiel AL, Foster AB, Rosso LD, Mendoza SP, Capitanio JP (2015) Cortisol in mother's milk across lactation reflects maternal life history and predicts infant temperament. Behav Ecol 26:269-281

Hrydy SB (1974) Male-male competition and infanticide among the langurs (Presbytis entellus) of Abu, Rajasthan. Folia Primatol 22:19-58

Johnson CN (1988) Dispersal and the sex ratio at birth in primates. Nature 332:726-728

Kaufman KJ, Hall JA (1989) Influence of the social network on choice and duration of breast-feeding in mothers and preterm infants. Res Nurs Health 12:149-159

Kay RF (1978) Molar structure and diet in extant cercopithecoids. In: Butler PM, Joysey KA (eds) Development, function and evolution of teeth. Academic Press, London, pp 309-339

Kennedy GE (2005) From the ape's dilemma to the weanling's dilemma: Early weaning and its evolutionary context. J Hum Evol 48:123-145

Kleiman DG (1981) Correlations among life history characteristics of mammalian species exhibiting two extreme forms and monogamy. In: Alexander RD, Tinkle DW (eds) Natural selection and social behavior. Chiron Press, New York, pp 332344

Koenig B, Markl H (1987) Maternal care in house mice. Behav Ecol Sociobiol 20:1-9

Kong S, Zhang S, Chen Y, Wang W, Wang B, Chen Q, Duan E, Wang H (2012) Determinants of uterine aging: lessons from rodent models. Sci China Life Sci 55:687-693

Künkele J, Kenagy GJ (2013) Inefficiency of lactation in primiparous rats: the costs of first reproduction. Physiol Zool 70:571-577

Lang SLC, Iverson SJ, Bowen WD (2012) Primiparous and multiparous females differ in mammary gland alveolar development: implications for milk production. J Exp Biol 215:2904-2911

Laurien-Kehnen C, Trillmich F (2004) Maternal food restriction delays weaning in the guinea pig, Cavia porcellus. Anim Behav 68:303-312 
Lee PC (1984) Ecological constraints on the social development of vervet monkeys. Behaviour 91:245-262

Lee PC (1996) The meanings of weaning: growth, lactation, and life history. Evol Anthropol 87-96

Lee PC, Kappeler PM (2003) Socioecological correlates of phenotypic plasticity of primate life histories. In: Kappeler PM, Pereira ME (eds) Primate life histories and socioecology. University of Chicago Press, Chicago, IL, pp 41-65

Lee PC, Majluf P, Gordon I (1991) Growth, weaning and maternal investment from a comparative perspective. J Zool 225:99-114

Leigh SR, Shea BT (1996) Ontogeny of body size variation in African apes. Am J Phys Anthropol 99:43-65

Love OP, McGowan PO, Sheriff MJ (2013) Maternal adversity and ecological stressors in natural populations: The role of stress axis programming in individuals, with implications for populations and communities. Funct Ecol 27:81-92

Low BS (1978) Environmental uncertainty and the parental strategies of Marsupials and Placentals. Am Nat 112:197-213

Lunn NJ, Arnould JPY (1997) Maternal investment in Antarctic fur seals: Evidence for equality in the sexes? Behav Ecol Sociobiol 40:351-362

Lycett JE, Henzi SP, Barrett L (1998) Maternal investment in mountain baboons and the hypothesis of reduced care. Behav Ecol Sociobiol 42:49-56

McDonald IR, Lee AK, Bradley AJ, Than KA (1981) Endocrine changes in dasyurid marsupials with differing mortality patterns. Gen Comp Endocrinol 44:292-301

McNeilage A (1995) Mountain gorillas in the Virunga volcanoes: ecology and carrying capacity. PhD-thesis, University of Bristol

McNeilly AS (1979) Effects of lactation on fertility. Br Med Bull 35:151-154

McNeilly AS, Tay CCK, Glasier A (1994) Physiological mechanisms underlying lactational amenorrhea. Ann NY Acad Sci 709:145-155

Meder A (1990) Sex differences in the behaviour of immature captive lowland gorillas. Primates 31:51-63

Miller N, Delbecchi L, Petitclerc D, Wagner GF, Talbot BG, Lacasee P (2006) Effect of stage of lactation and parity on mammary gland cell renewal. J Dairy Sci 89:46694677

Nowell AA (2005) Behavioural development in wild Western lowland gorillas. PhDthesis, University of Liverpool

Nowell AA, Fletcher AW (2007) Development of independence from the mother in 
Gorilla gorilla gorilla. Int J Primatol 28:441-455

Nowell A, Fletcher A (2008) The development of feeding behaviour in wild western lowland gorillas (Gorilla gorilla gorilla). Behaviour 145:171-193

Nozaki M, Mitsunaga F, Shimizu K (1995) Reproductive senescence in female Japanese monkeys (Macaca fuscata): age- and season-related changes in hypothalamicpituitary-ovarian functions and fecundity rates. Biol Reprod 52:1250-1257

Parker ST (1999) The life history and development of great apes in comparative perspective. In: Parker ST, Mitchell RW, Miles HL (eds) The mentalities of gorillas and orangutans: Comparative perspectives. University of Cambridge Press, Cambridge, pp 43-69

Pennington R, Harpending H (1988) Fitness and fertility among Kalahari !Kung. Am J Phys Anthropol 77:303-319

Piedrahita P, Meise K, Werner C, Krüger O, Trillmich F (2014) Lazy sons, selfsufficient daughters: are sons more demanding? Anim Behav 98:69-78.

Pusey A, Williams J, Goodall J (1997) The influence of dominance rank on the reproductive success of female chimpanzees. Science 277:828-831

Quinn EA (2013) No evidence for sex biases in milk macronutrients, energy, or breastfeeding frequency in a sample of filipino mothers. Am J Phys Anthropol 152:209-216.

Reiter J, Stinson NL, Le Boeuf BJ (1978) Northern elephant seal development: The transition from weaning to nutritional independence. Behav Ecol Sociobiol 3:337367

Reitsema LJ (2012) Introducing fecal stable isotope analysis in primate weaning studies. Am J Primatol 74:926-939

Robbins AM, Gray M, Basabose A et al (2013) Impact of male infanticide on the social structure of mountain gorillas. PLoS ONE 8:e78256

Robbins AM, Robbins MM, Fawcett K (2007a) Maternal investment of the Virunga mountain gorillas. Ethology 113:235-245

Robbins AM, Robbins MM, Gerald-Steklis N, Steklis HD (2006) Age-related patterns of reproductive success among female mountain gorillas. Am J Phys Anthropol $131: 511-521$

Robbins MM (1995) A demographic analysis of male life history and social structure of mountain gorillas. Behaviour 132:21-47

Robbins MM, Robbins A, Gerald-Steklis N, Steklis HD (2005) Long-term dominance relationships in female mountain gorillas: strength, stability and determinants of rank. Behaviour 142:779-809 
Robbins MM, Robbins AM, Gerald-Steklis N, Steklis HD (2007b) Socioecological influences on the reproductive success of female mountain gorillas (Gorilla beringei beringei). Behav Ecol Sociobiol 61:919-931

Romero LM (2004) Physiological stress in ecology: Lessons from biomedical research. Trends Ecol Evol 19:249-255

Roosevelt T (1913) Theodore Roosevelt: an autobiography. Macmillan, New York

Royle NJ, Hartley IR, Parker GA (2004) Parental investment and family dynamics: Interactions between theory and empirical tests. Popul Ecol 46:231-241

Sapolsky RM (1982) The endocrine stress-response and social status in the wild baboon. Horm Behav 16:279-292

Schaller G (1963) The mountain gorilla - ecology and behavior. University of Chicago Press, Chicago, IL

Sevi A, Taibi L, Albenzio M, Albenzio M, Muscio A, Annicchiarico G (2000) Effect of parity on milk yield, composition, somatic cell count, renneting parameters and bacteria counts of Comisana ewes. Small Rumin Res 37:99-107

Simpson MJ, Simpson AE (1982) Birth sex ratios and social rank in rhesus monkey mothers. Nature 300:440-441

Smuts B, Nicolson N (1989) Reproduction in wild female olive baboons. Am J Primatol 246:229-246

Stewart KJ (1981) Social development of wild mountain gorillas. University of Cambridge, Madingley

Stewart KJ (1988) Suckling and lactational anoestrus in wild gorillas (Gorilla gorilla). J Reprod Fertil 83:627-634

Symington MM (1987) Sex ratio and maternal rank in wild spider monkeys: when daughters disperse. Behav Ecol Sociobiol 20:421-425

Tait DEN (1980) Abandonment as a reproductive tactic. Am Nat 115:800-808

Tanaka I (1997) Parity-related differences in suckling behavior and nipple preference among free-ranging Japanese macaques. Am J Primatol 42:331-339

Therneau T (2015) Package “coxme”, version: 2-2.5., https://cran.rproject.org/web/packages/coxme/coxme.pdf

Tierney EP, Sage RJ, Shwayder T (2010) Kwashiorkor from a severe dietary restriction in an 8-month infant in suburban Detroit, Michigan: Case report and review of the literature. Int J Dermatol 49:500-506

Trillmich F (1986) Maternal investment and sex-allocation in the Galapagos fur seal, Arctocephalus galapagoensis. Behav Ecol Sociobiol 19:157-164 
Trivers RL (1972) Parental investment and reproductive success. In: Campbell B (ed) Sexual selection and the descent of man 1871-1971. Aldine Publishing Company, Chicago, IL, pp 136-179

Trivers RL (1974) Parent-offspring conflict. Am Zool 14:249-264

Trivers RL, Willard DE (1973) Natural selection of parental ability to vary the sex ratio of offspring. Science 179:90-92

Tutin CEG, Fernandez M (1993) Composition of the diet of chimpanzees and comparisons with that of sympatric lowland gorillas in the Lopé reserve, Gabon. Am J Primatol 30:195-211

Valeggia C, Ellison PT (2004) Lactational amenorrhoea in well-nourished Toba women of Formosa, Argentina. J Biosoc Sci 36:573-595

van Noordwijk MA, Kuzawa CW, van Schaik CP (2013) The evolution of the patterning of human lactation: A comparative perspective. Evol Anthropol 22:202212

van Noordwijk MA, van Schaik CP (2005) Development of ecological competence in Sumatran orangutans. Am J Phys Anthropol 127:79-94

Vedder AL (1984) Movement patterns of a group of free-ranging mountain gorillas (Gorilla gorilla beringei) and their relation to food availability. Am J Primatol 7:73-88

Watts DP (1980) Ecology of gorillas and its relation to female transfer in mountain gorillas. Int J Primatol 11:21-45

Watts DP (1984) Composition and variability of mountain gorilla diets in the Central Virungas. Am J Primatol 7:323-356

Watts DP (1989) Infanticide in mountain gorillas: new cases and a reconsideration of the evidence. Ethology 81:1-18

Watts DP (1994) Social relationships of immigrant and resident female mountain gorillas, II: Relatedness, residence, and relationships between females. Am J Primatol 32:13-30

Watts DP (1998) Long-term habitat use by mountain gorillas (Gorilla gorilla beringei).

1. Consistencey, variation, and home range size and stability. Int J Primatol 19:651-679

Watts DP (2000) Causes and consequences of variation in male mountain gorilla life histories and group membership. In: Kappeler PM (ed) Causes and consequences of variation in group composition. Cambridge University Press, Cambridge, pp 169-179

Watts DP, Pusey AE (1993) Behavior of juvenile and adolescent great apes. In: Pereira 
ME, Fairbanks LA (eds) Juvenile primates: life history, development and behavior. Oxford University Press, New York, pp 148-167

Whitten PL (1983) Diet and dominance among female vervet monkeys (Cercopithecus aethiops). Am J Primatol 5:139-159

Wijndaele K, Lakshman R, Landsbaugh JR, Ong KK, Ogilvie D (2009) Determinants of early weaning and use of unmodified cow's milk in infants: a systematic review. J Am Diet Assoc 109:2017-2028

Williams GC (1966) Natural selection, the costs of reproduction and a refinement of Lack's principle. Am Nat 100:687-690

Xiccato G, Trocino A, Sartori A, Queaque PI (2004) Effect of parity order and litter weaning age on the performance and body energy balance of rabbit does. Livest Prod Sci 85:239-251

Yamagiwa J (1987) Intra- and inter-group of an all-male group of Virunga mountain gorillas. Primates 28:1-30

Yamagiwa J, Kahekwa J, Basabose AK (2009) Infanticide and social flexibility in the genus Gorilla. Primates 50:293-303

\section{Table and Figure captions}

Table 1 Distribution of study offspring ( $>2$ years) across the five field periods including offspring which were weaned by the end of a given field period and offspring which either died or were not yet weaned at the end of a given field period (unknown weaned age)

Table 2 Number of silverbacks, (sub)adult females and total number of group members of study groups for each field period

Table 3 Outcome summary of effects on weaned age including all offspring. $H R$ presents hazard ratio and "*" indicate p-values equal or less than 0.05

Figure 1 Weaned age distribution in mountain gorillas 
Figure 2 Cox regression plot showing the proportion of non-weaned offspring in onemale and multi-male groups until the age of 60 months $(\mathrm{N}=69)$. Note that the survival curves include offspring who were not yet weaned in the end of the study period

Figure 3 Boxplot of offspring weaned age (in month) presented by a offspring sex (F female, $\mathrm{M}$ male) and $\mathbf{b}$ offspring sex and female rank (H high, L low) $\left(N_{H F}=6, N_{H M}=\right.$ 7, $N_{L F}=6, N_{L M}=11$ ). Boxplots indicate the median, the inter-quartile range, the maximum and minimum value excluding outliers

Figure 4 Distribution of offspring weaned age by mother's mean age (black vertical lines separate young, mid-aged, old mothers) and parity (empty dots = primiparous, black dots $=$ multiparous $)$

Figure 5 Relationship between weaned age (in months) and subsequent inter-birth interval $(N=20)$

Figure 6 Timing of subsequent conception date $(y=0)$ in relation to completed weaning. Negative values indicate weaning after conception and positive values indicate weaning before conception

Figure 7 Boxplot of offspring weaned age (in months) presented by survival of subsequent offspring $\left(N_{\text {survived }}=13, N_{\text {died }}=5\right)$. Boxplots indicate the median, the inter-quartile range, the maximum and minimum value excluding outliers and outliers showing data points less or more than 1.5 times outside the lower or upper quartile respectively 
